\title{
DOCUMENTOS
}

\section{La enseñanza institucional terciaria y las músicas populares ${ }^{1}$}

\author{
por \\ Coriún Aharonián \\ Compositor, Montevideo, Uruguay \\ gracor@adinet.com.uy
}

\begin{abstract}
Cuando uno ha estado hablando y escribiendo sobre educación y música durante varias décadas, se enfrenta habitualmente con el fantasma del peligro de repetirse. Confío en que hoy logre saltear ese peligro, y espero contar con la complicidad de aquellos de ustedes que conozcan ya algo de lo que he publicado en torno al tema.

Trataré de recorrer diversos puntos de la amplia temática que nos ocupará en estos días, abriendo las puertas de dos o tres de ellos para intentar describir los problemas de los que he tomado conciencia alguna vez. Obviamente, no estaré refiriéndome a situaciones concretas de la carrera de esta Universidad, puesto que la desconozco totalmente, así como desconozco otras carreras terciarias de música popular que se han iniciado en la Argentina en estos últimos años.

Dejo constancia, ya desde este primer momento, de mi discrepancia con la utilización de la expresión "formación académica" en el título de este congreso, discrepancia que comuniqué en el momento de ser invitado. A fin de evitar las múltiples confusiones que conlleva el término (desde la mera descalificación ${ }^{2}$ hasta el franco insulto ${ }^{3}$ ) voy a optar por hablar de formación institucional terciaria, entendiendo aquí como equivalentes los conceptos de terciario y de universitario. Sé que los organizadores del encuentro entienden mi punto de vista, y he recibido una clara respuesta al respecto ${ }^{4}$ :
\end{abstract}

\footnotetext{
${ }^{1}$ Conferencia dictada en el I Congreso Latinoamericano de Formación Académica en Música Popular. Universidad Nacional de Villa María, Córdoba, Argentina, 16-V-2007.

${ }^{2}$ El Diccionario de la Real Academia Española anota que, dicho de una obra de arte o de su autor, "académico" significa "que observa con rigor las normas clásicas", es decir, lo que todo artista debe evitar para que sus obras no se conviertan en meras copias de productos de un pasado muerto. "El riesgo, el experimento, la negación de las reglas inveteradas y caducas, son elementos esenciales de la actividad artística", escribe Hans-Joachim Koellreutter. "El pasado es un medio y un recurso, de ningún modo un deber. El futuro, sin embargo, sí lo es". ("O ensino da música num mundo modificado". Koellreutter 1980 y 1997.

${ }^{3}$ En 1968, Juan Carlos Paz rechazó airadamente su nominación como miembro de la Academia Nacional de Bellas Artes de la Argentina, al considerar esa nominación un insulto a su permanente lucha contra el academicismo. Curiosamente, el diario Clarín, en su informe del 9-XII-1968 sobre los nueve nominados, definía a Paz como "antiacadémico", sin detectar la contradicción implícita.

${ }^{4}$ De Silvia Aballay, el 29-IX-2006.
} 
"La intención del título del congreso es justamente plantear el gran dilema[:] cómo formar en la universidad en música popular sin desvirtuarla".

Quiero dedicar esta conferencia a Olga Villar y a Óscar Bazán, a Óscar oriundo de Cruz del Eje y a Olga nacida y criada aquí, en Villa María, donde se enamoró de Óscar, uno de los compositores más originales de América Latina en la década del 1970.

\section{UNO}

Un primer aspecto a considerar es el de los objetivos. Y ya aquí se nos complica el camino. La música popular no es un ente fijo ni estático ni único. Tal como lo predenunciaba con elegancia Carlos Vega en su ensayo de $1965^{5}$, es un terreno del quehacer cultural que posee una enorme capacidad de penetración en la sociedad, y puede incidir en ella tanto en los procesos de homogeneización -por imposición de modelos- como en los de diferenciación de colectividades. Es, pues, una formidable arma política, tanto para el ataque (por parte de los sometedores) como para la defensa (de los sometidos). (Y también para el contraataque de los sometidos, y el intento de neutralizarlo por parte de los sometedores). Cuando escogemos los materiales para el proceso docente, estamos desde un comienzo zambulléndonos, nos guste o no, en ese juego dialéctico.

$\mathrm{Al}$ asumir la enseñanza de algún aspecto tendiente a la formación de un futuro músico popular, es esencial recordar que lo que queremos es formar, precisamente, un músico popular. Un buen músico es un buen músico. Un señor con un diploma no es necesariamente buen músico, si no lo demuestra haciendo música. $\mathrm{Al}$ asumir esta responsabilidad desde un nivel terciario, le estamos diciendo a la comunidad, obviamente, que buscamos la excelencia en esa formación. Bien, y ¿qué define la excelencia de un músico popular? ¿Qué rasgos caracterizan a un músico popular excelente, es decir, un músico popular acerca de cuyo alto nivel de calidad exista consenso? No es fácil hacer la lista de esos rasgos. Y una de las funciones de la formación de un aspirante a músico popular debería ser la creación del hábito de discutir las calidades, abierta, desprejuiciadamente, con inteligencia y sobre todo con sensibilidad. ¿Por qué João Gilberto es excelente como intérprete? ¿Por qué lo son Osvaldo Pugliese o Aníbal Troilo como intérpretes y como compositores? ¿Por qué es excelente Enrique Santos Discépolo como letrista y como compositor? ¿Por qué lo es Chico Buarque como intérprete, como compositor y como letrista? ¿Por qué se ha homenajeado tanto, desde distintas tiendas, a Dámaso Pérez Prado, medio siglo después de su momento de esplendor? ¿Por qué es excelente Bola de Nieve? ¿Y Violeta Parra? ¿Por qué son excelentes Los Beatles o José Afonso?

¿En qué es excelente uno u otro de ellos? ¿Quién es excelente globalmente, quién es excelente específicamente como compositor, o como letrista, o como cantante, o como instrumentista, o como arreglista? ¿Qué pasa con Carlos Gardel? Entonces, ¿qué aspectos de la personalidad de un muchacho deberían ser más contemplados en un plan de estudios que propenda a acercarlos lo más posible a

\footnotetext{
${ }^{5}$ Aharonián 1997.
} 
esos modelos de excelencia? Quizás la velocidad de los dedos - ¿según qué patrón?, quizás la emisión vocal - ¿según qué patrón?, seguramente no la ambición de éxito- que no puede ser un objetivo sino, eventualmente, una consecuencia, probablemente sí el intelecto, sin duda la sensibilidad, necesariamente la disciplina de trabajo, por supuesto el amor por la gente que lo rodea en la sociedad a la que pertenece. Y esto, sobre todo porque un músico, como cualquier artista, es sobre todo un resultado de un contexto social, y es sobre todo con ese contexto social que se establecerá su relación dialéctica básica de trabajo.

Por otra parte, es fundamental recordar siempre que no existe una música popular sino que existe una enorme multiplicidad de músicas populares, aun en territorios y poblaciones muy pequeños. Y esas diferentes músicas populares pueden desempeñar papeles muy contradictorios, por lo que es muy desaconsejable acercarse al terreno con prejuicios, y muy poco útil para la construcción del futuro músico el no ayudarlo a abrir sus oídos a toda la amplia gama de variedades. Un rock puede ser extranjerizante pero puede no serlo, puesto que lo roquero, extranjero en la década del 1950, ya está instalado en la sociedad latinoamericana, y en algunos casos -no muchos- ha generado especies musicales locales suficientemente diferenciadas del modelo imperial ortodoxo -cuyo objetivo fue el de actuar como factor homogeneizador. Por otra parte, un rock metropolitano analizado en su contexto originario puede darnos una lección en materia de afirmación identitaria- allí, en su contexto. Una polca puede ser una forma de afirmación de regionalismo en un músico entrerriano, pero la polca también vino del imperio, sólo que mucho antes que el rock, y tuvo la maleabilidad de provocar polcas locales de espíritu claramente diferenciado. Una cueca puede ser una forma de afirmación de lo propio, pero puede significar -contradictoriamente- una forma de regresión a un pasado-feto falseado y mitificado. Una baguala o una vidala puede ser un elemento identitario pero, según cómo se la trate, puede convertirse en una apropiación indebida, dentro del propio país, de un potencial despojador frente al indefenso despojado. Mientras tanto, el aprendizaje de la particularísima emisión vocal del sistema cultural del noroeste argentino, de clara raíz prehispánica, puede ser útil para sacudirse de encima, de alguna manera y en alguna medida, los esquemas de emisión vocal impuestos y bendecidos por el sistema de poder.

Aquí aparece un nuevo aspecto: el ético. Y su primera manifestación: el respeto. El respeto al prójimo - individuo o sociedad, el respeto a uno mismo, el respeto por el hecho musical en sí. El respeto al prójimo se puede sintetizar en dos frases: yo no tengo derecho a subestimar lo hecho por el otro, y no tengo derecho a echarle encima a los demás algo que no sea producto de mis mejores esfuerzos. El respeto a uno mismo también se puede sintetizar: no puedo permitirme el no rendir al máximo de mis posibilidades. Y el respeto por el hecho musical en sí puede ser explicado en forma sencilla mediante una pregunta insidiosa: si no siento respeto por aquello a lo que se supone que dedico mi vida, ¿por qué no me dedico a otra cosa por la que realmente sienta respeto?

Un cuarto aspecto: la música popular -en realidad, toda música- no está fija en el tiempo, sino que, estando viva, cambia permanentemente. Se realimenta 
con su propio pasado ${ }^{6}$, toma elementos de otras áreas musicales; incluida la música culta, incorpora recursos o soluciones de otras culturas.

\section{DOS}

Claro que todo esto debe aparecer en los procesos educativos. Tanto para el aspirante a compositor como para el aspirante a compositor-intérprete (la categoría más habitual en música popular de nuestra parte del mundo) como para quien desea ser meramente intérprete, es importantísimo el despertar el interés por el descubrimiento de lo que otros han hecho y hacen en materia de música popular. Sin evitar ni lo que el sistema escamotea ni tampoco lo que el sistema machaca día y noche. La franja etaria del estudiante terciario es probablemente la más proclive a abrir oídos, con entusiasmo, a hechos desconocidos o poco conocidos. Superada la etapa adolescente, caracterizada en términos generales por la necesidad de escoger un modelo -o de aceptarlo pasivamente- y de copiarlo en todos sus aspectos, incluidos los no musicales que aparezcan asociados con ese modelo (ropa, peinado, gestos, etcétera), el postadolescente empieza a sentir la necesidad de ser individuo él mismo. Lo peligroso es que se trampee a ese joven y se le haga permanecer en una etapa de mera copia (como hacen los institutos de tipo Berklee College of Music), en la que los géneros musicales son cajoncitos preestablecidos (anclados por lo tanto en el pasado y por ello momificados) ${ }^{7}$, y para los cuales hasta la improvisación es el aprendizaje de recetas.

En un momento de la cultura occidental en el que se hace lo posible por estirar la adolescencia y demorar la maduración del individuo, el papel de los mecanismos educativos puede ser absolutamente decisivo en ayudar a ese estudiante a hacerse adulto, en este caso por la vía de aprender que hay muchos modelos posibles, y que es fundamental conocerlos y asumir la responsabilidad de ser uno mismo.

Esto se vincula por otra parte con uno de los aspectos centrales del objetivo educacional: he citado reiteradamente en estos últimos años el título de un inteligente libro de la educadora uruguaya Reina Reyes: “¿Para qué futuro educamos?”8. América Latina produce permanentemente excelentes músicos, pero al no estar las instituciones educativas al servicio de un proyecto de futuro propio, la mayor parte de esos músicos jóvenes se sienten estafados en y por su propio país, y pasan a engrosar las filas de la fuga de cerebros hacia el Primer Mundo. No hay

${ }^{6}$ También lo observaba Carlos Vega.

${ }^{7}$ Aquí se abre un tema muy amplio: el de los cajoncitos. Por alguna razón práctica, la enseñanza de música popular se hace a menudo en cajoncitos: tango, jazz, rock, folclorismo (o "proyección folclórica", pero no "folclore", por favor, que es otra cosa). Los cajoncitos sirven para formar en interpretación, es cierto, siempre y cuando se centren en el aprendizaje específico de las técnicas específicas. Pero -al margen de la imperiosa necesidad de conocer las especies musicales propias y ajenas- la cosa es distinta en el campo de la composición: ¿por qué obligar a crear dentro de géneros cerrados, que ya son, inevitablemente, del pasado? No se compone en cajoncitos si es que realmente se quiere tener la puerta abierta hacia el futuro. Ni Firpo ni De Caro ni Pugliese ni Piazzolla ni Yupanqui ni los Ábalos ni Leguizamón hubieran existido si hubieran triunfado los cajoncitos.

${ }^{8}$ Reyes 1987. 
lugar en el mundo hoy día donde no aparezca por lo menos un músico argentino. La Argentina no los produjo en función de sus necesidades de futuro, pero tampoco exactamente en función de las necesidades del imperio, sino en función de la nada. En la Argentina -o en Chile o en Colombia o en México o en Brasil o en Uruguay- ese joven, al terminar su etapa de formación, no encuentra vías para una inserción en la realidad de su país. Pero no se le ocurre cuestionar el proceso formativo que lo llevó a ese callejón sin salida. La conclusión habitual es "este es un país de mierda”. Y se va a un país que él cree que no es de mierda. Allí, su amor propio de emigrado le va a jugar variadas malas pasadas, y nos encontraremos a menudo con músicos latinoamericanos trabajando en cualquier cosa que no admitirían en su propio país, situación que se da en otros campos también, por supuesto. El propio Primer Mundo es experto en producir lo que ellos llaman "proletariado académico": arquitectos o médicos que trabajan como taximetristas, si tienen suerte, o como lavaplatos si no la tienen. Claro que no hay cursos para ser un buen taximetrista -sabido es que alguien que estudió para cirujano o para urbanista adquirió todas las habilidades para manejar un taxi y tratar a sus usuarios- ni para ser un buen lavaplatos, porque una falsa y ridícula jerarquización de estos tiempos lleva a presuponer que hay oficios dignos y oficios indignos, hasta de ser aprendidos.

Para los países ricos -que son ricos a cuenta de lo que nos roban en el ordenamiento colonial-, malgastar dineros públicos para generar un proletariado académico es estúpido e irresponsable. Para nosotros, en el Tercer Mundo, es criminal. Claro que nosotros somos pícaros y le encontramos la vuelta, aprendida de los del norte: al que egresa de un curso universitario y no logra inserción natural en la sociedad, le aseguramos un puestito en la cadena universitaria: dará clase a otros que egresarán para dar clase a otros que egresarán para dar clase a otros que egresarán para dar clase a otros. Y también podremos exportar al Primer Mundo esta mano de obra para cuya capacitación el Primer Mundo no ha gastado un centavo.

“Hoy, educar para el presente-que no otra cosa hacemos-es educar para un pasado que nunca volverâ" 9 , señala Reina Reyes; "quienes acceden al poder económico o al poder político están interesados en mantener su poder y, por lo mismo, tanto la educación privada como la pública, que directa o indirectamente controlan, tienden a conservar la estructura social que los mantiene en su situación de privilegio", continúa. "Es grave, gravísimo, que los países subdesarrollados de América Latina imiten las prácticas educativas de los países desarrollados, sin apreciar que el colonialismo vacía y distorsiona la mente e incapacita al hombre para liberarse de los poderes económicos que lo dominan". Antes, había escrito: "Descubrir el grado en que los medios de comunicación enajenan al hombre, en lugar de liberarlo, es tarea que apremia [...]. Resignarse al poderío de lo económico es actuar en su favor en lugar de tener por meta la liberación del hombre”. Hasta aquí Reina Reyes.

${ }^{9}$ En el original, esta oración es subrayada por la propia Reina Reyes (1987:13). 
Un problema básico de la enseñanza institucional es precisamente su condición de institucional. Hasta ahora, las instituciones de enseñanza de lo creativo en materia musical -y en otras áreas también- han demostrado no ser especialmente fértiles. Y han resultado en general castradoras de la creatividad que deberían haber potenciado. El antropólogo Daniel Vidart contaba la siguiente broma en forma de diálogo: “SSatán! ¡Encontré la verdad! ¡Estamos perdidos!” "No te preocupes, que enseguida la institucionalizo" 10 . ¿Se puede neutralizar esta condición destructiva de lo institucional? Entiendo que sí. Al menos, hay que intentarlo. Si mantenemos clara la conciencia de los objetivos, es probable que logremos ir neutralizando algunos de los aspectos perniciosos de las estructuras institucionales.

Por ejemplo, en la potenciación de lo creativo y en la relativización de la importancia de lo imitativo. Aun en las artes interpretativas. Maurizio Pollini no es un pianista excepcional porque imite maravillosamente bien a, por ejemplo, Arthur Rubinstein, sino porque es, en sí, un intérprete de impecable técnica al servicio de ideas musicales que están regidas por el respeto a aquello que se interpreta, se trate de Chopin o de Debussy o de Luigi Nono. Por ejemplo, en la potenciación de futuros arreglistas que sean capaces de ser también no coloniales, no imitativos, no epigonales. Por ejemplo, en la potenciación de lo cualitativo en detrimento de lo cuantitativo, y no al revés, que es lo habitual. No es mejor un guitarrista que toca muchas notas por segundo, sino aquel que toca bien las notas que toca, sean muchas o muy pocas. Como Raúl García Zárate, como Daniel Viglietti. Como Atahualpa Yupanqui, que nunca aceptó hacer segundas tomas en sus grabaciones de París $^{11}$, y que nos deja claro para siempre que la prolijidad de plástico no es lo primordial en música.

Por ejemplo, en una formación lo más completa posible, que logre vencer la falta de información respecto al todo. Es importante no sólo que el futuro músico popular sepa qué ocurre en el total del acontecer de la música popular, en el mundo, sí, y especialmente en América Latina, doblemente sí, sino que es importante que sepa qué ocurre en paralelo en el total de la música culta. Y no sólo la de ayer y anteayer, que es lo que habitualmente se ocupa de informar la academia, especialmente a través de sus materias específicas, como armonía, anclada en un pasado momificado, sino la de hoy, la de hoy-hoy, que de todos modos ya será ayer apenas ese estudiante finalice sus estudios. El conocimiento a fondo de ésa de ayer y anteayer puede ser incluso de poca importancia, desde que la propia música popular de ayer y anteayer ha tenido en cada momento su diálogo horizontal con ella.

Cuchi Leguizamón, una de las figuras más creativas de la música popular argentina, se alimentó en una útil alternancia entre una tradición no esclerosada y un presente tan informado de la música popular como de la música culta (cuya resultante es una música en la que lo melódico y lo armónico son concebidos

${ }^{10}$ Comunicación personal en Montevideo, 13-VI-2005.

${ }^{11}$ Testimonio de los técnicos de Le Chant du Monde, 1974. 
desde el arranque como una sola cosa). "Satie es un viejo espléndido. Es el viejo más joven de la música”, dice en 1988. “¡Cómo hubiera escrito yo la Chacarera de la Muerte si no hubiera conocido a Schoenberg!"12. El pianista de jazz Enrique Villegas decía con humor en 1966, refiriéndose a la personalidad más radical de la vanguardia de la música culta en la Argentina ${ }^{13}$ : "Con Juan Carlos Paz me une un gran afecto, dado que alcanzamos ambos la misma altura. Él en jazz y yo en música dodecafónica. Porque, aunque ninguno de los dos lo sabe, él siempre ha tratado de escribir jazz y yo música dodecafónica”. Eduardo Lagos, un importante innovador de la década de 1960, estudió en su adolescencia con el propio Juan Carlos Paz ${ }^{14}$. En Brasil, Hans-Joachim Koellreutter -introductor allí del dodecafonismo, como Paz en la Argentina- tuvo un papel fundamental en la formación (y potenciación) de varias generaciones de músicos populares, desde Tom Jobim hasta Chico Mello, pasando por los músicos tropicalistas.

\section{TRES}

El cuidado por los procedimientos incluye aspectos materiales concretos. Es imposible dar clases de instrumentos en grupos grandes, y es imposible darlas si no hay suficientes instancias de sesiones individuales. Un instrumento no se enseña en el pizarrón. Sin embargo hay burócratas de la enseñanza que protestan porque un profesor de violín o de trompeta malgasta su sueldo dedicando una hora semanal a cada uno de sus alumnos. Es imposible dar clases de composición en grupos de veinte alumnos, aunque haya estructuras universitarias, en nuestro continente, que pretendan que un profesor dicte clase de orquestación a un grupo de ochenta muchachos.

La experiencia dice que es mejor una clase de composición en grupo que individual, entre otras razones porque se establece una relación de trabajo profesor-alumno menos vertical (inevitable en una clase individual), hay más posibilidad de que se discutan las supuestas verdades y cada alumno tiene oportunidad de conocer varias soluciones a un mismo problema planteado (la suya y las que aportan sus compañeros). A veces las clases individuales funcionan, pero la mayor parte de las veces rinde más el trabajo en grupo. Así como el tiempo de clase de un curso de idioma no suele exceder los 45 o 60 minutos, el tiempo de clase de un curso de composición -cuyo formato más conveniente es el de taller-no debe ser muy corto. El taller necesita un complemento de seminario, en paralelo o en simultáneo. Un trabajo de seminario para informar sobre música y para discutirla resulta correcto con sesiones de dos horas-reloj, entre otras razones porque la música transcurre en el tiempo. Tanto en un seminario institucional sobre músicas populares como en un curso de idioma, puede ser conveniente tener dos sesiones semanales, pero en un taller de composición parece ser aconsejable no tener más de una, a fin de dar tiempo a los trabajos domiciliarios. Según el número de integrantes del grupo, según la idiosincrasia de éstos y según el grado de

\footnotetext{
${ }^{12}$ Espinosa 2000 (www.raicesargentinas.com.ar/Notas/reportajes/cuchi.htm).

${ }^{13}$ Schóó 1966.

${ }^{14}$ Testimonio personal, 2005.
} 
avance en el trabajo de cuestionamiento de los trabajos, una duración para una clase semanal de composición, en mecanismo de taller, puede variar entre 90 minutos y dos horas o más (en este caso, con una interrupción para un café, claro). Si se decidiera hacer una experiencia mixta de seminario y taller, el tiempo de trabajo que se siente como necesario puede ir en aumento hasta maratones de cuatro o cinco horas. Obviamente, esto implica una entrega muy grande en los alumnos y una entrega mayor todavía en el docente. Un alumno que no se conmueva realmente frente a hechos musicales no va a poder sobrevivir tiradas tan extensas. Un docente que no se apasione por la docencia -y antes por la músicano va a poder sostener una clase tanto tiempo seguido. La experiencia dice, por otro lado, que en el trabajo de taller de composición el grupo no debe exceder los siete $\mathrm{u}$ ocho integrantes. Ya ocho empieza a ser, a los efectos de una clase de composición, multitud. El número ideal está entre tres (dos es demasiado poco, y tres está justo en el límite) y seis (cuatro o cinco parece ser un número ideal). Curiosamente, docentes que han trabajado en otras áreas de la formación terciaria/universitaria han llegado a conclusiones muy parecidas. En un terreno tan aparentemente alejado como la medicina, por ejemplo ${ }^{15}$.

\section{CUATRO}

Para ser un buen instrumentista de música popular, un joven necesita dominar técnicamente su instrumento. Pero cuando el aprendizaje no ha sido ya resuelto por la vía directa, ¿cuál es la técnica que la institución de enseñanza debe trasmitirle a ese joven? En algunos instrumentos, la técnica de la tradición culta europea no dista mucho de la que se necesita para tocar bien un tango, pero si el músico es pianista, no le alcanzará con ser un gran virtuoso como Daniel Barenboim para que los conocedores lo acepten en su fraseo tanguero. De todos modos, para ser pianista de tango, es muy probable que una buena base de técnica culta europea le resulte útil ${ }^{16}$.

Puede ser importante que el futuro instrumentista tenga una buena formación solfeística -pero no antediluviana-. Sin embargo, en buena parte de su actividad el instrumentista popular irá perdiendo la necesidad de la lectura. En algunos terrenos de la música popular y en algunos instrumentos le será útil aprender a decodificar tablaturas, es decir, cifrados.

\footnotetext{
${ }^{15}$ Elena y otros 1992.

${ }^{16}$ Se abre aquí, claro, otro tema que es importante también en música culta: ¿cuál es la forma de trasmitir una técnica instrumental? Barenboim se pronuncia contra la enseñanza de escalas y ejercicios similares. Más de un siglo y medio antes (en un texto de 1832 que citaremos más adelante), Juan Bautista Alberdi proclama: "Las primeras lecciones de piano no serán probablemente ni penosas escalas, ni ejercicios cansados. La marcha más frecuente de las manos es más bien salteada que sucesiva, y ejercitar a uno en escalas para marchar [luego] de un modo irregular, es lo mismo que adiestrarlo en la carrera para que aprenda a bailar. No hay una cosa más árida y difícil que una escala, mientras que hay pocas cosas más inútiles: muy rara vez ocurren en el curso de una pieza (al menos a dos manos) y es lo primero que se pone a un discípulo; iy no se le pone una ni dos, sino que se le presentan veinticinco! En esto se invierten comúnmente tres y cuatro meses: ;sobrado tiempo efectivamente para que el más paciente se aburra y deteste la música por toda su vida!” Suárez Urtubey 2006:22.
} 
Por otra parte, la formación de instrumentistas no debería ser terciaria: hay instrumentos que se deben aprender antes de la finalización de la edad de crecimiento, puesto que necesitan de la deformación de ciertos músculos y articulaciones.

Si se trata de un cantante, la problemática es más compleja. ¿Qué modelo de emisión de la tradición culta europea le va a servir? ¿El operístico? No, pues no tiene vigencia en ninguna de las músicas populares de los últimos cien años, ni de las latinoamericanas ni de las propiamente europeas. En la propia Italia, algún fenómeno comercial de ese tipo explotado de tanto en tanto por las empresas discográficas apuntará fundamentalmente a un público mediopelo. Gardel viene de la refinadísima técnica del estilo rioplatense ${ }^{17}$, como Razzano, como Corsini. Apoyándose en referencias muy diversas, brasileñas y extranjeras, la bossa nova inventa sus reglas de juego, que van a permanecer largo rato. El canto de los llaneros venezolanos y colombianos, ¿a qué modelo responde? ${ }^{18}$. Entonces, ¿qué le puede dar la enseñanza institucional al aspirante a cantante? Deberá ser cuidadosa, para que lo que trasmita sea lo realmente universal, lo fisiológico, lo referente a la salud vocal, sin interferir en la estética de la emisión. Y dejando un buen margen de libertad para que, por ejemplo, si es mujer y hace folclorismo en el Cono Sur, pueda diferenciarse del pesadísimo modelo de Mercedes Sosa. De paso, ¿cuánto de solfeo necesita un cantante popular? En nuestra sociedad actual, aun entre los cantantes profesionales de ópera hay quienes leen con mucha dificultad, al tiempo que, en la misma tradición culta europea, los cantantes de lied suelen ser muy buenos lectores $-y$ tienen muy poco vibrato-y los integrantes de conjuntos vocales dedicados a la música del pasado o a la contemporánea son necesariamente excelentes en ese terreno -y su vibrato es aún menor-.

Instrumentista y cantante deberán ir aprendiendo el mecanismo que se establece, en esta cultura occidental posterior a las revoluciones burguesas, entre escenario y sala. Mecanismo de posesión (del artista sobre el público) que, manejado con sentido ético, funcionará de manera menos autoritaria que lo que el sistema querría. Deberán ir aprendiendo a ser individuos y a ser, al mismo tiempo, grupo. Deberán ir aprendiendo también cómo son los mecanismos de comunicación y de difusión de su trabajo en esta sociedad, para poder ser -también en este terreno- lo más libres posibles, mientras la trama de poder de las transnacionales y de sus aprendices regionales se agiganta permanentemente.

Un arreglista va a necesitar manejar un bagaje de conocimientos un poco más intrincado. Obviamente, necesitará ser un buen solfeísta -si su trabajo va a estar destinado a músicos de sesión, lectores de primera vista- y un buen "cifrista" -si, por ejemplo, va a dedicarse a trabajar con roqueros-. Una formación como compositor le será muy útil, y un curso de instrumentación también. Pero de nada le servirá lo aprendido si no tiene capacidad para detectar reglas de juego en el género en el que se esté moviendo, y si no tiene capacidad para, eventualmente, innovarlas, dialogando con quien sea el responsable final del producto musical,

${ }^{17}$ Aharonián 1989.

${ }^{18}$ Peñín 1993. 
que en América Latina es, en general, el intérprete, o el autor-intérprete. O capacidad para mediar creativamente entre autor e intérprete.

Un compositor necesita potenciarse como creador, no como repetidor. Y ahí está el principal problema institucional. ¿Necesita armonía y contrapunto el aspirante a compositor? Según qué se entienda por tales palabras. Obviamente, quien asista a un taller de composición deberá previamente estar manejando con soltura los conceptos solfeísticos de la comunicación entre músicos y los conceptos armónico-contrapuntísticos necesarios para saber de qué se habla cuando se dice "cadencia" o cuando se dice "tritono" o cuando se dice "subdominante-dominante-tónica”. Pero hasta ahí llega lo realmente necesario. En música culta instrumental, dadas las características de la praxis de codificación en partitura, este conocimiento deberá ser un poco más extenso, más alargado. Curiosamente, no si el compositor desea dedicarse exclusivamente a la música electroacústica, en la que estará lidiando directamente con el resultado sonoro y no con su decodificación. Pues bien, en música popular, también el compositor debe lidiar más con el resultado sonoro que con su eventual codificación, que es, casi siempre, aproximada. Una partitura de tango o de jazz tocados por quien no sobreentienda las reglas de juego de ese terreno musical, va a sonar a música de tía vieja, cuadrada, sin swing.

A un aspirante a compositor de música culta le alcanza, en el nivel terciario, con un año de una materia que conjugue armonía y contrapunto, es decir, todo lo relacionado con la estructuración vertical del sonido. Torturar al alumno con años de armonía por un lado y de contrapunto por otro, es sádico, y amenaza con castrar al futuro músico ${ }^{19}$. Una práctica coral o de conjunto vocal pequeño da mejor la vivencia de las posibilidades de estructuración armónico-contrapuntística. Pero hecha con criterio quietista o con repertorio limitado puede correr el peligro de anclar esa vivencia en un pasado culto europeo ficto, en vez de potenciarla hacia el futuro. Un seminario-taller de posibilidades de estructuración horizontal-vertical que hicimos con Graciela Paraskevaídis hace más de dos décadas permitió una fascinante aventura en la que se recorrieron desde los lenguajes modales con o sin bordón hasta el hoquetus pigmeo, desde el hoquetus de Machaut hasta el gamelán indonesio, desde el riguroso orden comunitario de las culturas altiplánicas hasta situaciones aguisimbias o negro-africanas, desde la lógica de Juan del Encina o la de Giovanni Gastoldi hasta las de la generación europea de la segunda posguerra.

Un muchacho que, a través de la sensibilización de la audición de determinado lenguaje, haya entendido la lógica interna de una estructura horizontal-vertical, va a poder completar casi sin error las partes que se le escamoteen, mientras que aquel que la haya recibido por vía de supuestas reglas logrará probablemente

${ }^{19} \mathrm{El}$ comunicar a los alumnos -e imponer- las materias, armonía y contrapunto como universalmente inherentes a lo musical, no sólo los condiciona a una percepción de la música desde el punto de vista de la momificación de la música culta europea del pasado remoto, sino que perjudica la comprensión de la propia música culta europea contemporánea, además de obstaculizar la de las músicas populares mestizas de las Américas de los últimos dos siglos, y, por supuesto, la de las músicas extraeuropeas. 
una aproximación torpe y poco musical. A menudo llegan muchachos a un taller de composición diciendo "después de este acorde viene éste, ¿verdad?". No han aprendido a escuchar a los grandes creadores, para los cuales esa pregunta no rige jamás. Es más: normalmente, a falta de una actualización de la academia, lo que se enseña en un curso de armonía es el resabio de las supuestas reglas del período de Bach, establecidas por un mal compositor con poder de convicción en el sistema educativo de las épocas que siguieron. Los alumnos más obedientes no llegan a descubrir nunca por qué la música de Bach no respeta esas reglas, por qué ya los hijos de Bach consideran tales reglas obsoletas, y por qué Haydn las despatarra cada vez que se le ocurre. En música popular, en las últimas décadas, ese conocimiento de una supuesta armonía barroca se alarga con cursos complementarios de armonías "modernas", que intentan cuadratizar aquello que debería surgir como desarrollo de la sensibilidad auditiva -y corporal- del estudiante. Los jóvenes que vienen de la guitarra, actualmente mayoría, suelen entender erradamente la armonía -que reciben como algo sagrado- como una sucesión de palos de alambrado, sin lograr entender muchas veces que un proceso armónico es una continuidad de líneas simultáneas; y uno contrapuntístico también. Unos y otros no llegan a descubrir que lo armónico, tal como la academia lo repite, viene de un período determinado de la historia de la música de Europa occidental, el que converge con el tonalismo, y no es una cualidad en sí de la música, ni siquiera de la europea antes o después del período de vigencia de esa lógica armónico-tonal. Tampoco llegan a descubrir que buena parte de la música popular de América, aun la muy mestizada con lo europeo, responde en gran medida a mecanismos lógicos no armónico-tonales. Descondicionar luego a esos muchachos para ayudarlos a ser libres toma por lo menos un año y medio de trabajo docente.

Juan Bautista Alberdi, importantísima figura en la política argentina y sudamericana entre la década de 1830 y la de 1870 , escribe en $1832^{20}$, a sus 22 años de edad: "[...] efectivamente, la naturaleza [,] dotando al hombre de esa extraordinaria facultad de imitación, ha querido que aprenda a hablar antes de conocer la gramática; aprenda a pensar antes de conocer la lógica; aprenda a cantar antes de conocer la música; en fin, lo aprenda todo sin sospechar siquiera que hay reglas para aprenderlo. [...] Mi discípulo [...] sabrá tocar el piano antes de conocer una nota, del mismo modo exactamente como ha sabido hablar antes de conocer una letra, es decir, dándole ejemplo antes de darle reglas" ${ }^{21}$.

Compositor o arreglista o intérprete, un músico popular aprende sobre todo por la buena observación de lo que hacen o hicieron otros músicos populares. Normalmente, lo hace sin necesidad de la academia. Pero si una institución terciaria desea ser útil en la formación del músico popular, he ahí un terreno en el que va a tener que cuidar mucho su trabajo. Puede ayudar al muchacho a salirse del cerco de los medios de comunicación, puede ayudarlo a conocer lo actual "mundial", puede ayudarlo a conocer lo de su patria grande latinoamericana,

${ }^{20}$ Alberdi 1886 .

${ }^{21}$ Suárez Urtubey 2006: 20. 
puede ayudarlo a descubrir su patria chica, habitualmente escondida en América Latina y puede ayudarlo, sobre todo, a escuchar.

\section{CINCO}

En San Cristóbal, en las montañas de Venezuela, un muchachito talentoso y generoso era capaz de tocar magníficamente músicas del sistema del joropo, y de enseñar a tocar cada uno de los instrumentos envueltos en ellas. Pero puesto a componer para el grupo guerrillero que operaba en la zona, recibía pasivamente la visión deformada del quehacer musical que ofrecía el ambiente universitario vinculado con la guerrilla, que entendía la canción revolucionaria como una copia pasiva de las viejas canciones revolucionarias de Europa, con las cuales poco o nada tenían que ver los campesinos a quienes estaba destinada tal canción.

En Cuenca, en Quito, en Asunción, en Lima, en Santiago de Chile, en La Serena, en Ciudad de México, en Montevideo, en Buenos Aires, en Santa Fe, en Caracas, en Río de Janeiro, en San Pablo, en La Habana, no es más fácil resolver la problemática de qué hacer con el joven que quiere ser músico popular para que sea más útil a su sociedad, concepto -el de utilidad a la sociedad- que se opone, en principio, al de la búsqueda del éxito, que todos los mecanismos del establishment se desesperan por inculcarnos diariamente, a toda hora. El sistema universitario, si desea asumir esta responsabilidad, debe sopesar muy bien los ingredientes de sus planes ${ }^{22}$.

Y la idoneidad de sus docentes. Este año, el Congreso Argentino de Educadores Musicales organizado por el Fladem en Villa Regina, Río Negro, plantea como punto central de discusión la necesidad de que quien enseña música sea músico. Como en Medicina, es probable que un mal cirujano sea un excelente docente y que un excelente cirujano sea un pésimo docente. Pero en términos generales, suele ocurrir que un buen cirujano tiene mejores posibilidades de trasmitir el oficio.

\section{SEIS}

En esta acelerada cabalgata, tratemos de ver algunas situaciones metodológicas de taller concretas.

\footnotetext{
${ }^{22}$ En Cuenca, en la alta montaña del sur del Ecuador, la universidad ha empezado a incidir en la formación de músicos populares, pero los muchachos no reciben la información mínimamente necesaria que los sitúe en el ahora y en el aquí. En Quito, la capital, la Municipalidad financia una orquesta de muchos instrumentos que toca malos arreglos de música popular convencional. En Asunción, todavía planean sobre la gente los resultados del genocidio que argentinos, brasileños y uruguayos cometimos en el Paraguay en el siglo XIX, para favorecer la política del imperio británico. Los muchachos son apocados, tienen en general una gran vergüenza de ser paraguayos, y no se animan a lanzarse al agua. Salvo algún ejemplo aislado, que los países vecinos nos encargamos de que no trascienda. En Bogotá y en otras ciudades de Colombia, la academia ha ido aumentando mucho su injerencia en la formación de músicos, y eso se oye a menudo en un endurecimiento de la riquísima música popular, en una rigidización en que se tocan notas pero a veces falta la música, en una alienante dicotomía entre lo del imperio y lo tradicional propio.
} 
A. En la etapa adolescente, como decíamos, el muchacho escucha una sola cosa que ha escogido -o que lo ha escogido-y la copia. Pasada esa etapa, y habiendo ya desembarcado en una etapa sicológica más madura, puede ser muy interesante incitar al alumno a "sacar" una canción de la escucha de una grabación. Elegido adecuadamente el ejemplo, sea éste puntual -"para la próxima aprendete El arriero por Yupanqui”- o genérico -"para la próxima tráete aprendida (para cantarla y tocarla en clase) una canción cualquiera que sea música de Yupanqui y esté interpretada por Yupanqui”-, el resultado en una situación de taller puede ser muy enriquecedor. Se podrá observar qué es lo que el aprendiz de músico ha aprendido ya a detectar (por ejemplo, los detalles melódicos o de fraseo, las sutilezas armónicas -que es probable que sean sólo dominante y tónica-, los detalles de texto, las relaciones entre el canto y el toque de guitarra) y se le podrá inducir a empezar a descubrir otras cosas. Es probable que descubra que acaba de empezar a descubrir esa música o ese músico. Esto, llevado al plano de la escritura, puede depararnos muchas sorpresas, la primera de las cuales va a ser el asombro ante la enorme complejidad de lo que parecía tan simple. La mayor parte de los estudiantes universitarios puestos a pautar en el pentagrama lo que hace, por ejemplo, Atahualpa Yupanqui, no logrará completar la tarea, al menos en un plazo de algunos días. Para su aprendizaje de aquello que definíamos como el respeto, este tipo de mecanismos docentes puede convertirse en un recurso muy efectivo.

B. Es esa base ética de respeto, junto con la base meramente técnica de lograr escuchar mejor lo que acontece con lo que hace determinado músico popular, la que va a permitir una praxis más sana y constructiva de uno de los aspectos del quehacer del músico popular intérprete: esa etapa particular de la música popular que no es ni lo puramente compositivo ni lo puramente interpretativo, sino algo creativo que está en el medio y que en general llamamos "versión", aunque el término no nos convenza -y mientras nos llega uno que lo sustituya satisfactoriamente $^{23}$. Es interesante encargar a los muchachos una franca "versión" de tal pieza, una misma pieza para todo el grupo. Si los alumnos son todos guitarristascantantes, se puede pedir una difícil tarea: hacer una versión en canto y guitarra de una pieza originariamente para canto y guitarra.

C. Una parte de los compositores de canciones populares compone en general la música sobre un texto preexistente, en todo o en parte. Para desarrollar esta capacidad, es muy útil plantear en taller la musicalización de un texto que se convenga de común acuerdo (hay diversos mecanismos para esto, fuera de la imposición lisa y llana de un texto: desde las propuestas varias del docente para que los alumnos escojan una de ellas, hasta la votación entre propuestas varias aportadas por los propios alumnos). Es lindísimo ver -para los alumnos pero también para el profesor- cómo surgen soluciones diferentísimas para algo que, a priori, pudiera parecer monolítico. Y cómo va afirmándose poco a poco la personalidad del joven, dándole gradualmente idea de sus características individuales de personalidad frente a los otros compañeros. Con grupos suficientemente maleables y con

${ }^{23}$ Aharonián 1990. 
textos que se prestasen a ello ${ }^{24}$, he planteado etapas de insistencia: hecha la primera musicalización, pedir una segunda musicalización distinta del mismo texto y, a veces, hecha la segunda musicalización, pedir una tercera.

$\mathrm{CH}^{25}$. Otra parte de los compositores de canciones populares escribe en general la letra sobre una música que componen antes (tal es el caso de Chico Buarque) o piden a un colega esa letra sobre la música que ellos han compuesto (es el caso de João Bosco y, en algunos casos, también de Chico). Este camino parece más difícil de resolver en ejercicios de clase, pero puede ser tan sorprendente en sus resultados como el anterior.

D. Vinculado con los dos primeros puntos, tenemos el terreno de lo arreglístico. Hoy día los recursos que la informática le ofrece al alumno en su propio domicilio ayudan mucho a entrar en este terreno sin tener que limitarse a la decodificación imaginada de una escritura en papel. Obviamente, la discusión de lo arreglístico se debería dar tanto con materiales ajenos como con materiales propios, lo cual no es necesariamente más fácil ${ }^{26}$. La problemática de la identidad cultural plantea entre nosotros, a menudo, desafíos imprevistos. Uno de ellos es el del respeto (nuevamente el respeto) por los instrumentos que no encajan dentro de la plantilla de la orquesta europea. Una quena o un charango o un par de sikus o un par de las flautas llamadas "gaita" en Colombia o una marimba de chonta o una marímbula merecen tanto respeto por sus reglas propias de juego como un piano de cola o un violonchelo ${ }^{27}$.

E. Mencionado el campo de la informática, es obvio que la tecnología debe ser, sí o sí, un área que el aspirante a músico popular debe manejar hoy día con toda soltura. Desde los conocimientos de acústica y sicoacústica, que le permitan quizás entender mejor por qué tal o cual recurso puede desencadenar determinada situación perceptiva, hoy se hace imprescindible empujar al joven músico a relacionarse con naturalidad con las posibilidades que le brinda la tecnología, sin hacerse dependiente de ella y sí logrando que la máquina le obedezca.

F. La tarea plenamente compositiva puede tratarse ya a través de los trabajos espontáneos que los integrantes del grupo traigan de su repertorio ya compuesto -o en vías de composición-, como de encargos con determinada consigna que unifique los problemas a ser resueltos por igual por todos, lo que ayudará a una

\footnotetext{
${ }^{24}$ Un buen poema no es necesariamente una buena letra de canción. Es más: en la mayor parte de los casos suele no serlo.

${ }^{25}$ Aunque la Real Academia haya eliminado la letra che, me parece importante insistir en rescatarla.

${ }^{26}$ Puede ser muy enriquecedora la lectura de los trabajos de Philip Tagg sobre este ámbito, estudiado especialmente en sus significados.

${ }^{27}$ No han faltado en los últimos tiempos los despistados que han intentado "mejorar" quenas haciéndolas cromáticas y poniéndoles llaves, o temperando la marimba de chonta, o cromatizando el arpa paraguaya, o transformando el par de sikus comunitario en uno único, curvo como la flauta pánica rumana, y cromático. El daño que esos despistados le pueden hacer a las desprotegidas culturas de América es incalculable. No se trata de congelar el pasado, sino de permitir a los instrumentos indígenas y mestizos que hagan su propio camino, sin injerencias de los mecanismos de poder institucional que, sin percibirlo, estén destruyendo cosas esenciales.
} 
discusión más profunda. Un crítico de música popular recordaba hace poco en una revista ${ }^{28}$, que un antiguo alumno mío tuvo que hacer determinada canción como desafío de clase frente al hecho de haberse fracturado un brazo y tenerlo enyesado: le encargué resolver la composición para que pudiera ser tocada a pesar del yeso. En el Río de la Plata, donde la bailabilidad no es socialmente muy importante, por lo menos en los ámbitos pequeñoburgueses, pedir al grupo componer una canción que sea bailable resulta un verdadero desafío. O componer una canción en la que la primera persona sea del otro sexo. O hacer una canción con acordes perfectos mayores, o sólo con dominante y tónica, o una modal con bordón. O crear una canción erótica (una de las cosas más difíciles de lograr en la cultura criolla de América del Sur), o armar una canción con una sola nota, o dos, o tres, o una canción que sea atonal y no suene a rara, o que sea francamente dodecafónica sin pegar saltitos a la Webern, o tantos otros desafíos que seguramente han practicado muchos de los participantes de este congreso desde hace mucho tiempo. Lo más fascinante es que, como en los talleres de composición culta, el profesor suele equivocarse medio a medio. Mi comentario en "A redoblar" fue "esta parte es incantable". A la gente le importó poco y la canción se transformó en el himno de la resistencia contra la dictadura en Uruguay.

\section{SIETE}

Finalmente, quisiera referirme muy sucintamente al posible contenido de un trabajo de seminario. Si bien en música culta es habitual informar sobre el proceso histórico de la tradición europea occidental, a la que la música culta pertenece, en música popular ese recorrido histórico se hace imposible si se lo quiere proyectar a los siglos anteriores al XX, porque no existían procedimientos de grabación, y porque sabemos que las pocas partituras existentes no reflejan exactamente lo que sonaba. Pero aún limitándonos al siglo XX, una historia general de la música popular del sistema cultural impuesto por Europa desde su proceso de expansión imperialista, es casi impracticable por lo excesivamente extensa y por la carencia de una bibliografía de fácil acceso que ayude a abarcar un terreno tan amplio y tan intrincado. Recuérdese que hasta Carlos Vega la musicología en general se negaba a estudiar las músicas populares, con excepción de las tradicionales que se clasificaban como folclóricas ${ }^{29}$.

${ }^{28}$ Inzillo 2006.

${ }^{29}$ Cuya mejor definición era probablemente la que daba Lauro Ayestarán hacia 1965, haciendo una inteligente y clara síntesis de lo escrito hasta entonces. Para Ayestarán, folclore "es la ciencia que estudia las supervivencias culturales -espirituales y materiales- de patrimonios desintegrados que conviven con los patrimonios existentes o vigentes". Para él, la "nota básica" del folclore -y, por supuesto, de la música folclórica como consecuencia- "es el hecho de la supervivencia”. Las otras características (las "notas caracterizadoras") usadas habitualmente para definir el terreno pueden existir o no: una supervivencia puede ser un hecho "tradicional, oral, funcional, colectivo, anónimo, espontáneo, vulgar". Pero "[lo] fundamental es eso: la supervivencia”. Lo otro, la música popular que se apoya en las expresiones folclóricas, quedaba naturalmente definida como "folclorismo" o-como preferían algunos folclorólogos argentinos- como "proyección folclórica". 
Pero necesitamos que el aspirante a músico popular aprenda a conocer, a descubrir, a analizar, no académicamente, por favor, lo referente a, precisamente, la música popular. Y para ello necesitamos generar un ámbito de información, de escucha atenta, de análisis abierto, de discusión. Si la materia "formas musicales" es confusa en música culta, a pesar de una bibliografía aparentemente abundante, se hace varias veces más confusa en música popular. La zamba del noroeste argentino tiene una forma muy clara, de ahí la no pertinencia de escribir sus letras en cuartetas cuando se trata en realidad de unidades de seis frases, tanto en las dos partes A de cada mitad como en la parte B. Pero es muy difícil definir qué forma tienen otras especies de música popular. Y el espectro de posibilidades puede ir desde las estructuras adiscursivas, reiterativas o no, a las estructuras discursivas no occidentales, como las del raga de la India. O las occidentales, dentro de las cuales podríamos ver como caso básico las de tipo pregunta-respuesta como Arrorró mi niño, frente a las que la zamba es más sutil y más compleja, aunque sea también del tipo genérico pregunta-respuesta. Ese mismo sobreentendido que permite romper la expectativa, como en Yellow submarine. O intercalar dos discursos paralelos y semánticamente convergentes, como en parte de las vidalas.

El juego mayor-menor -acomodamiento de una importantísima percepción no tonal de las culturas populares de América- nos plantea serios desafíos para su sistematización. La rítmica mestiza de América -que los centros de poder pretenden adoptar desde la conquista en adelante y lanzan al mundo cada tanto tiempo- posee muchos elementos que resultan incompatibles con las soluciones de escritura musical de la música europea occidental. En términos generales, necesitamos generar en la praxis un solfeo y un análisis que partan de la propia realidad de la música popular de nuestro tiempo y no de los apriorismos de los "conservadores" de la academia de la música culta europea del pasado remoto.

Lo interesante en el terreno de un trabajo de seminario es que, sea cual fuere la unidad temática que escojamos con un mínimo de inteligencia, estaremos muy pronto discutiendo prácticamente toda la problemática que el muchacho deberá enfrentar como músico popular. Y, aquí, puede darse un interesante diálogo entre propuestas del docente de las que los alumnos deberán escoger una, y contrapropuestas de los alumnos, de entre las cuales el docente deberá ver cuál se anima a abordar. Es una materia que puede llevar mucho tiempo de preparación y de estudio al docente, pero cuyos frutos son realmente inestimables. Hay tantas posibilidades de discutir la problemática entera del músico popular en un seminario sobre la historia del rock, como en uno sobre Los Beatles en particular, o como en uno sobre la bossa nova, o sobre Caetano Veloso, o sobre el folclorismo argentino desde la década de 1950, o sobre la historia del tango, o sobre el tango cantado en las décadas de 1930 y 1940, o sobre la música popular cubana de las décadas de 1940 y 1950, o sobre Violeta Parra, o sobre el rock argentino de las últimas tres décadas, o sobre la canción francesa de mediados del siglo XX, o sobre los festivales de San Remo, o sobre la canción relacionada con Bertolt Brecht, o sobre el vals peruano, o sobre Matilde Casazola, o sobre Simón Díaz, o sobre... 


\section{$\mathrm{OCHO}$}

Para finalizar, citaré un diálogo que formó parte del espectáculo que Jorge Lazaroff $^{30}$ y Leo Maslíah ${ }^{31}$ hicieran en 1984 en Montevideo y Buenos Aires bajo el título de "Recital irrestricto”. Lazaroff tenía 34 años y Maslíah 30.

[Lazaroff canta "Ahí mar nomás".]

- L. M.: Hay una parte que no me convence cómo está resuelta armónicamente. - J. L.: ¿Cómo?

- L. M.: Esa parte... Perdoná, yo creo que la crítica tenés que tomarla como una cosa constructiva, ¿no?, como una cosa... que es para bien. No te ofendas por lo que te voy a decir. Pero esa parte que dice "va Ramón ahí va marrón”...

-J. L.: Sí...

- L. M.: A mí se me ocurren dos opciones, sustitutivas de cómo vos la hacés. [Al piano.] Podés hacer, por ejemplo, dominante-tónica, y decís [canta] "va Ramón ahí va marrón". O, si no, hacés tónica-dominante [al piano] y decís [canta] "va Ramón ahí va marrón”. Pero esa mezcla que vos hiciste de las dos cosas, no se usa. - J. L.: [Pausa.] Sí, es cierto, sí. Qué horror. [Pausa.] ¡No se usa!

- L. M.: Además, es muy trágica como la tocás vos, creo. O sea, ¿por qué no la tocás en Mi mayor, en lugar de tocarla en ese Mi menor medio revirado que vos usás?

- J. L.: ¿Te parece que es muy trágica? Claro, sí, si la hago en mayor [en la guitarra], me da... Claro, el mayor es la tonalidad alegre y el menor es la tonalidad triste. Sí, puede ser, sí. A ver, entonces vos querés que yo la haga... [toca y canta] ¿Así?

- L. M.: Ahí está, claro.

- J. L.: ¿Te parece?

- L. M.: Mejora. Así mejora un poco. Pero el problema es el ritmo, aparte, que es medio dislocado, ¿no? ¿Por qué no lo trabajás un poco, el ritmo?

- J. L.: Y sí, es un... es un ritmo irregular.

- L. M.: Y bueno, ¡regularizalo!

- J. L.: Pero ¿te parece? Estuve tanto tiempo tratando de liberar un poco el cuerpo, y eso... ¿Te parece, sí?

- L. M.: Trabajalo un poco más. Yo creo que lo podés acomodar. Tratá.

- J. L.: A ver. Así que vos querés que lo haga en mayor, que lo haga dominantetónica y con un ritmo regular. [Canta y toca.] ¿Algo así?

- L. M.: Ahora sí. Ahora sí, ;por fin! ¡Ahora sí se parece a algo!

\section{REFERENCIAS BIBLIOGRÁFICAS}

AHAROnián, Coriún

1989 "Gardel cantante de estilos". La Hora Popular, Montevideo (24 de junio).

1990 "Direccionalidad sociocultural y concepto de versión en mesomúsica" (informe). V Jornadas Argentinas de Musicología y IV Conferencia Anual de la Asociación Argentina de Musicología, Buenos Aires, 1990. Mecanoscrito.

${ }^{30}$ Lazaroff 1984a y 1984b.

${ }^{31}$ Maslíah 1984. 
1997 "Carlos Vega y la teoría de la música popular: un enfoque latinoamericano en un ensayo pionero", Revista Musical Chilena, LI/188(julio-diciembre), pp. 61-74.

Alberdi. J. B.

1832 Ensayo sobre un método nuevo para aprender a tocar el piano con la mayor facilidad. Buenos Aires, Reproducido en: Obras completas, tomo I. H. Congreso de la Nación, Buenos Aires, 1886.

Elena, Rocardo y OTROS

1992 Formación médica en la comunidad. Nordan, Montevideo, 1992.

ESPINOSA, ROBERTO E.

2000 "Al sueño del 'Cuchi' nadie lo puede enlazar" (entrevista a Gustavo Leguizamón). La Gaceta de Tucumán, San Miguel de Tucumán, fecha no identificada. Reproducido Raíces Argentinas, sitio internet, hacia 2000 (www.raicesargentinas.com.ar/ Notas/reportajes/cuchi.htm).

Hans-Joachim Koellreutter.

1980 “O ensino da música num mundo modificado". Caderno de Música, № 2, São Paulo, octubre, pp. 6-8.

1997 "O ensino da música num mundo modificado". Educação Musical / Cadernos de Estudo, $\mathrm{N}^{\circ}$ 6, Belo Horizonte, febrero, pp. 37-42.

INZILLO, HuMPHREY

2006 "Dulzura distante". Rolling Stone, № 103, Buenos Aires, octubre.

LAZAROFF, JORGE

1984a “¿?". Asamblea, Montevideo, 6 de diciembre, pp. 22-23.

1984b “e?”. La del Taller, № 1, Montevideo, diciembre, pp. 10-12.

MASLÍAH, LEO

1984 Un detective privado ante algunos problemas no del todo ajenos a la llamada música popular. Taller Argentino de Música Popular, Rosario de Santa Fe.

PeÑín, José

1993 "En los llanos resuena el eco de los castrati”. Revista Bigott, № 25, I/III, Caracas.

REYES, REINA

1987 Para qué futuro educamos. Biblioteca de Marcha, Montevideo, 1971. 4ª ed. revisada, Banda Oriental, Montevideo.

SCHÓó, ERNESTO

1966 "Paz: Lo que dice y lo que dicen”. Primera Plana, Buenos Aires (31 de mayo).

Sú́rez Urtubey, Pola

2006 Juan Bautista Alberdi. Teoría y praxis de la música. Secretaría de Cultura de la Nación, Buenos Aires. 